\title{
Neutron Diffraction Study of Gas Adsorption and Separation in Metal-Organic Frameworks
}

\author{
Hui $\mathrm{Wu}$ \\ NIST Center for Neutron Research, National Institute of Standards and Technology, \\ Gaithersburg, Maryland 20899-6102, United States
}

Porous metal-organic frameworks (MOFs) have shown great potential for many adsorption-related applications, including storage and separation of fuel gases $\left(\mathrm{H}_{2}, \mathrm{CH}_{4}, \mathrm{C}_{2} \mathrm{H}_{2}\right.$ etc.). Neutron diffraction is a technique complementary to $\mathrm{x}$-ray diffraction, in terms of characterizing the MOFs and investigating their gas adsorption structures. In some cases, neutron diffraction can provide unique information not available from $\mathrm{x}$-ray. In this talk, I will highlight some of our recent works on gas storage and separation in newly developed MOFs $\left(\mathrm{SiF}_{6}\right.$ containing MOFs, $\mathrm{UiO}$ analogue MOFs etc.), where neutron diffraction was found to play a unique and powerful role, by providing highly valuable structural and mechanistic insights. 